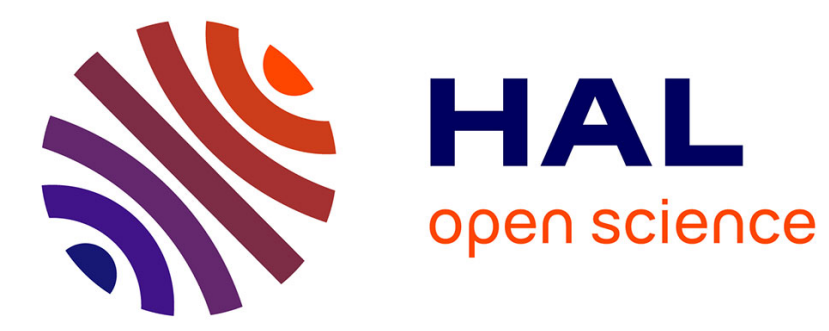

\title{
Introduction: Alternatives in semantics and pragmatics
}

Anamaria Falaus

\section{To cite this version:}

Anamaria Falaus. Introduction: Alternatives in semantics and pragmatics. Alternatives in Semantics, Palgrave Macmillan, pp.1-35, 2013, Palgrave Studies in Pragmatics, Language and Cognition, 9780230314344. hal-01158558

\section{HAL Id: hal-01158558 \\ https://hal.science/hal-01158558}

Submitted on 2 Jun 2015

HAL is a multi-disciplinary open access archive for the deposit and dissemination of scientific research documents, whether they are published or not. The documents may come from teaching and research institutions in France or abroad, or from public or private research centers.
L'archive ouverte pluridisciplinaire HAL, est destinée au dépôt et à la diffusion de documents scientifiques de niveau recherche, publiés ou non, émanant des établissements d'enseignement et de recherche français ou étrangers, des laboratoires publics ou privés. 


\section{INTRODUCTION: ALTERNATIVES IN SEMANTICS AND PRAGMATICS}

Anamaria Fălăuş

University of the Basque Country (UPV/EHU)

\section{ALTERNATIVES IN SEMANTICS AND PRAGMATICS}

In producing and interpreting sentences, speakers constantly process information about other things that could have been said. The alternative linguistic forms that a speaker chooses not to use often play a significant part in the grammaticality and felicity of an utterance in a given context. As a result, both semantic and pragmatic theories need to provide an explicit model of alternatives and their relation to assertions. The idea that the well formedness of sentences may be determined by a selection among competing forms or interpretations plays a key part in many linguistic phenomena and has been at the core of several theoretical frameworks. ${ }^{1}$ In semantics and pragmatics, the issue became more prominent when an increasing number of phenomena were argued to have a semantics that makes direct reference to alternatives. Among them, there are three main topics that have been extensively studied and constitute the primary sources of alternative semantics (i.e. semantics based on alternatives): questions (e.g. Hamblin 1973, Karttunen 1977, Groenendijk and Stokhof 1984, Hagstrom 1998, Shimoyama 2001, Lahiri 2002), focus (e.g. Rooth 1985, 1992, Beck 2006, Wagner 2006, Beaver and Clark 2008), and implicatures (e.g. Horn 1972, 1989, Gazdar 1979, Hirschberg 1985, Levinson 2000, Zimmermann 2000, Chierchia 2004, Sauerland 2004, Fox 2007, Geurts 2010). Although the range of applications of alternative semantics has been constantly expanding, these are the domains that have shaped the definition of alternatives as semantic/pragmatic objects. The proposed alternative-based accounts make use of alternative sets, but do not necessarily rely on a common set of assumptions regarding alternatives. As we will see shortly, there are at least three main issues on the basis of which alternative-based systems can be distinguished, namely how they conceive (i) the source of alternatives, (ii) the mechanism underlying the generation of propositional alternatives, and (iii) the relation between alternatives and the assertion.

The term alternative semantics (attributed by Rooth 1996 to von Stechow 1989) currently designates (at least) two different alternative-based systems. One of them, also called Hamblin semantics, goes back to the analysis of questions proposed in Hamblin (1973). On this view, all expressions have sets of alternatives as their unique semantic value, which then combine with other constituents of the sentence in a compositional manner. A different alternative-based theory of interpretation, originating in Rooth (1985), assumes a 'multi-dimensional' semantics: alongside standard meanings, speakers recursively build up alternative sets that are accessed by alternative sensitive-operators. In this set-up, alternatives are introduced and computed separately from the regular semantic values. In the following, we briefly summarize the use of alternatives in each of these two systems, staying as close as possible to the original discussions. Next, we turn to a closely related area of investigation, namely implicatures, where the correct definition of alternatives has been the subject of intense debates. The goal is to provide an overview of the use of alternatives in these three areas of semantics and pragmatics and thus set the basis for a comparison among existing alternative-based systems. We conclude this section by laying out some of the theoretical and empirical issues raised by the application of alternative semantics to an increasing number of phenomena and pointing out some of 
the questions that remain open at this stage. Section 2 summarizes the contents of the present volume and shows how the individual contributions address these issues.

\subsection{Questions}

Hamblin (1973) introduced the compositional computation of alternative sets to analyze questions in Montague grammar (without however employing the term alternative). On this account, the meaning of a question is the set of propositions that serve as its possible answers (see also Karttunen 1977, Groenendijk and Stokhof 1984, Hagstrom 1998, Shimoyama 2001, Lahiri 2002 among others)

(1) Who walks?

According to Hamblin, a question such as (1) denotes "a set, namely, the set whose members are the propositions denoted by 'Mary walks', 'John walks', ... and so on for all individuals. Pragmatically speaking, a question sets up a choice-situation between a set of propositions, namely, those propositions that count as answers to it" (Hamblin 1973:48). To compositionally derive this set of propositions, Hamblin proposes to replace denotations with denotation-sets, subsequently referred to as alternative sets (e.g. Ramchand 1997, Kratzer and Shimoyama 2002). For most lexical items, this amounts to equating their denotation to singleton sets of standard denotations: the semantic value of a proper name like Mary is $\{$ Mary\}, i.e. the set whose unique member is Mary, the semantic value of an intransitive verb like walk is a singleton set containing the property 'walk', etc. The more interesting consequence of the switch to denotation-sets concerns interrogative words like who and what, which on this account denote non-singleton sets of alternatives: the set of humans and set of nonhumans respectively. Once we adopt this perspective, the component parts of Mary left and Who left? are identical. The outcome is a unified treatment of interrogative and declarative sentences, which on this view are the same kind of formal object, namely sets of propositions. In both cases, the sets denoted by the various constituents of the sentence combine in a compositional manner, via pointwise functional application resulting in a (possibly singleton) set of propositions, as sketched in (2) and (3) below. The composition rules apply the denotation of leave to each member of the set with which it combines, yielding a set containing one proposition (2), or several propositions, one for each individual in the who set (3):
a. Mary left.
b. \{that Mary left $\}$
a. Who left?
b. $[[$ who $]]=\{x: x$ is a person $\}=\{$ Mary, Paul, Linda,$\ldots\}$
c. left $(\{$ Mary, Paul, Linda,... $\})=\{$ left (Mary), left (Paul), left (Linda), ... $\}$
d. \{that Mary left, that Paul left, that Linda left, ... \}

Hamblin's compositional analysis of questions constitutes the first attempt to use alternatives as a tool to formalize natural language constructions, but he didn't use it systematically nor did he explore this any further. His paper however set the basis for the analysis of questions as sets of propositions (i.e. alternatives), pursued in much subsequent work (see Krifka 2011 for an overview). Opinion has varied as to whether the denotation of questions should be equated to the set of true answers (e.g. Karttunen 1977) or the set of all possible answers (Hamblin 1973, Groenendijk and 
Stokhof 1984). The existing proposals also diverge on whether the relevant sets of propositions are derived by movement (Karttunen 1977) or not (Hamblin 1973).

More importantly for our present purposes, Hamblin's proposal also provided crucial insights for a non-movement, alternative-based analysis of wh-words in languages like Bengali (Ramchand 1997) or Japanese (e.g. Hagstrom 1998, Shimoyama 2001, and Kratzer and Shimoyama 2002). Wh-indefinites in these languages, commonly referred to as indeterminates (following Kuroda 1965), are known to acquire a different interpretation depending on the operators with which they associate (e.g. interrogative, negative, quantificational). The following examples, taken from Shimoyama (2006), illustrate this behavior:
a. Dono gakusei-mo odotta. which student-MO danced 'Every student danced.'
b. [Dare-ga odorimasu] ka? who-Nom dance Q 'Who dances?'

The hypothesis that indeterminates are alternative-introducing elements provides a natural way to capture this variability. To illustrate, let us briefly review the influential proposal due to Kratzer and Shimoyama (2002), which not only lays out the main components of a Hamblin semantics for Japanese indeterminates (building on Shimoyama 2001), but also constitutes the first detailed attempt to generalize this approach to a wider range of indefinites cross-linguistically. More specifically, on a par with interrogative words like who, indeterminate pronouns such as dare or dono are assumed to introduce sets of alternatives which expand (compositionally) until they find an operator that selects them. Alternatives can be of different types (e.g. individual, propositional) and as a consequence are accessible to both sentential and non-sentential (generalized) quantificational operators, which eventually determine the interpretation of the indeterminate. Crucially, the alternative-introducing element stays in situ, which means that there is no movement or binding relation between the operator and the alternatives it operates on. Their association is indirect and simply follows from the way semantic interpretation proceeds. As illustrated in (3) above, via (pointwise) functional application, individual alternatives can expand and give rise to alternatives of a higher type, e.g. propositional alternatives, which then get caught by a sentential operator, such as the ones in (5) (taken from Kratzer and Shimoyama 2002:8):

$$
\begin{aligned}
& \text { For }[[\alpha]]^{\mathrm{w}, \mathrm{g}} \subseteq \mathrm{D}_{<\mathrm{s}, \mathrm{t}}: \\
& \text { a. }[[\exists \alpha]]^{\mathrm{w}, \mathrm{g}}=\left\{\lambda \mathrm{w}^{\prime} . \exists \mathrm{p}\left[\mathrm{p} \in[[\alpha]]^{\mathrm{w}, \mathrm{g}} \text { and } \mathrm{p}\left(\mathrm{w}^{\prime}\right)=1\right]\right\} \\
& \text { b. }[[\forall \alpha]]^{\mathrm{w}, \mathrm{g}}=\left\{\lambda \mathrm{w}^{\prime} . \forall \mathrm{p}\left[\mathrm{p} \in[[\alpha]]^{\mathrm{w}, \mathrm{g}} \rightarrow \mathrm{p}\left(\mathrm{w}^{\prime}\right)=1\right]\right\}
\end{aligned}
$$

The contribution of the indeterminate remains constant, i.e. a set of alternatives, its different readings being the result of associating with different operators. When a set of propositional alternatives combines with the existential operator defined in (5a), it yields the proposition that is true in case at least one alternative in the relevant set is true. The universal quantifier defined in $(5 \mathrm{~b})$ yields the proposition that is true in case every alternative in the relevant set is true. Similar alternative-sensitive meanings are defined for other quantificational and propositional operators.

The proposed semantics is exploited to derive a wide range of properties: 
interpretational variability, locality restrictions, intervention effects or concord phenomena. For example, the alternatives introduce by an indeterminate expand until they meet a suitable operator such as interrogative $-k a$ or universal $-m o$. Since there is no movement involved, this kind of compositional system is not sensitive to island boundaries. Accordingly, there is nothing that would prevent the alternatives introduced by indeterminates within islands from being selected by an interrogative operator. But crucially, they must associate with the first available operator, without 'skipping' any possible operator, which explains why the configuration in (6), a typical intervention effect, is ruled out:

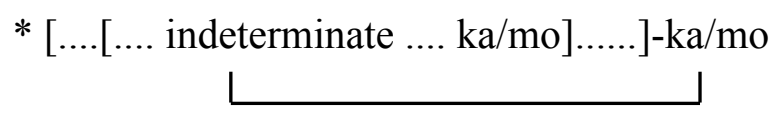

This briefly illustrates the way in which Hamblin semantics captures the behavior of indeterminates. This kind of alternative-based approach has been extended to indefinites which do not display a similar interpretational variability, but whose behavior is nevertheless sensitive to the presence of certain operators, such as negation or modals (e.g. Kratzer and Shimoyama 2002, Kratzer 2005; MenéndezBenito 2005; Yanovich 2005; Arregui 2006; Alonso-Ovalle and Menéndez-Benito 2010 among others). These accounts share the assumption that indefinites denote sets of (individual) alternatives, which grow compositionally and can be selected by different alternative-sensitive operators. The applications of the alternative-based framework proposed by Hamblin are not limited to interrogatives and indefinites. Other phenomena and constructions that received analyses couched in a Hamblin semantics include evidentials (Murray 2009), comparatives (Morzycki 2010), conditional structures (Rawlins 2008), or disjunction or other scalar terms (AlonsoOvalle 2006, Keshet 2006).

\subsection{Focus}

In contrast to the 'one-dimensional' system introduced by Hamblin, other theories of interpretation assume a 'multi-dimensional' semantics, where alternatives are kept separate from standard meanings. Rooth $(1985,1992)$ developed an influential alternative-based semantics for focus, in which the function of focus is to evoke alternatives (an intuition that goes back to Jackendoff 1972). On this theory, natural language expressions have two semantic values: an ordinary semantic value and a secondary, focus semantic value. The former is the regular semantic value assigned by the interpretation function, marked as $[[.]]^{0}$ in Rooth (1992), e.g. $[[\text { Mary }]]^{\circ}=$ Mary. The focus value of an expression - marked [[.] $]^{\mathrm{f}}$ - is the set comprising its alternatives, i.e. a set of meanings of the same semantic type (also referred to as $p$ sets). Rooth shows that the set of focus alternatives of a complex constituent can be derived compositionally by taking the focus values of its subconstituents and applying the usual semantic rules to them, as defined in (7) (taken from Rooth 1996:281):

(7) a. The focus semantic value of a focused phrase of semantic type $\tau$ is the set of possible denotations of type $\tau$.

b. The focus semantic value of a non-focused lexical item is the unit set of its ordinary semantic value.

c. Let $\alpha$ be a non-focused complex phrase with component phrases $\alpha_{1}, \ldots, \alpha_{k}$ and 
let $\phi$ be the semantic rule for $\alpha$, e.g. function application. The focus semantic value of $\alpha$ : is the set things obtainable as $\phi\left(\mathrm{x}_{1}, \ldots, \mathrm{x}_{\mathrm{k}}\right)$, where $\mathrm{x}_{1} \in\left[\left[\alpha_{1}\right]\right]^{\mathrm{f}} \wedge \ldots \wedge$ $\mathrm{x}_{\mathrm{k}} \in\left[\left[\alpha_{\mathrm{k}}\right]\right]^{\mathrm{f}}$

The focus semantic value of a non-focus marked constituent is equal to its regular denotation, or more precisely the singleton containing its regular denotation. If a constituent is focus marked, its focus semantic value is the set of alternative meanings construed by replacing the denotation of the focused expression with an object of the same semantic type. For illustration, consider the example in (8), with the ordinary semantic values in (8a) and the focus semantic values in (8b):

$\mathrm{JOHN}_{\mathrm{F}}$ saw Lisa.

a. $\left[\left[\mathrm{John}_{\mathrm{F}}\right]\right]^{\mathrm{o}}=\mathrm{John}$

$[[\text { Lisa }]]^{\circ}=$ Lisa

$[[\mathrm{saw}]]^{0}=\lambda y \cdot \lambda x \cdot \operatorname{saw}(x, y)$

$[[\mathrm{saw}]]^{\mathrm{O}}\left([[\mathrm{Lisa}]]^{0}\right)\left(\left[\left[\mathrm{John}_{\mathrm{F}}\right]\right]^{\mathrm{o}}\right)=\operatorname{saw}($ John, Lisa $)$

b. $\left[\left[\mathrm{John}_{\mathrm{F}}\right]\right]^{\mathrm{f}}=D_{e}$

$[[\text { Lisa }]]^{\mathrm{f}}=\left\{[[\text { Lisa }]]^{\mathrm{o}}\right\}=\{$ Lisa $\}$

$[[\mathrm{saw}]]^{\mathrm{f}}=\left\{[[\mathrm{saw}]]^{\mathrm{o}}\right\}=\{\lambda y \cdot \lambda x \cdot \operatorname{saw}(x, y)\}$

$[[\text { saw }]]^{\mathrm{f}}\left([[\text { Lisa }]]^{\mathrm{f}}\right)=\left\{[[\text { saw }]]^{\mathrm{o}}\left([[\text { Lisa }]]^{\mathrm{o}}\right)\right\}=\{\lambda x \cdot \operatorname{saw}(x, \operatorname{Lisa})\}$

$[[\text { saw Lisa }]]^{\mathrm{f}}\left(\left[\left[\mathrm{John}_{\mathrm{F}}\right]\right]^{\mathrm{f}}\right)=\left\{\operatorname{saw}(x, \operatorname{Lisa}) \mid x \in D_{e}\right\}$

The focus semantic value of the focused constituent is determined by the rule in (7a); since $\left[\left[\mathrm{John}_{\mathrm{F}}\right]\right]^{\mathrm{o}}$ is of type $e$, this is the set of individuals. The focus values of the nonfocused constituents Lisa, saw and saw Lisa consist of the singletons containing their respective ordinary semantic values, as defined in (7b). The VP combines through pointwise functional application with each member in the set of alternatives to John. This yields the focus value of the whole sentence, namely the set of propositions of the form $x$ saw Lisa, where $x$ is an entity.

Focus meanings are relevant for a variety of expressions in language, expressions which are said to associate with focus, e.g. focus-sensitive particles such as only or even. In Rooth's system, they operate over focus alternatives and incorporate them into the ordinary meaning of the sentences where they occur. Different positions of focus determine different alternative sets, which once combined with the lexical semantics of a focus-sensitive expression, result in different truthconditions. Consider the following examples:

a. John only introduced Bill to $[\mathrm{Sue}]_{\mathrm{F}}$.

b. John only introduced $[\text { Bill }]_{\mathrm{F}}$ to Sue.

The ordinary value of the two sentences is identical, unlike their focus values. According to the rules in (7) above, the focus value contains propositions of the form John introduced Bill to $x$ for (9a), and propositions of the form John introduced $x$ to Sue for (9b), where $x$ is a variable of type $e$. Once only is computed, the resulting meaning of (9a) is that "John introduced Bill to Sue" and any other proposition in the set of alternatives is false, i.e. John introduced Bill to Sue and to no one else. In (9b), only takes a different alternative set and the derived interpretation is "John introduced Bill and no one else to Sue". This provides a simple illustration of the truthconditional effect of focus-induced alternatives. 
Rooth's theory, in which focus introduces sets of alternatives, built up compositionally alongside standard meanings, has been applied to a variety of focusrelated phenomena. These include question-answer congruence, VP-ellipsis and anaphora, focus on contrastive pairs, focus-induced conversational implicatures, superlatives, generic sentences, or as illustrated above, the focus sensitivity of expressions like only, even, also or too (for extensive reviews, see e.g. Kadmon 2001, Beaver and Clark 2008, Hinterwimmer 2011).

As discussed in Rooth $(1992,1996)$, alternative semantics (similarly to another influential approach to focus, namely structured meanings, e.g. von Stechow 1991, Krifka 1992) is a useful tool in describing and characterizing the contribution of focus to the interpretation of a given focus-sensitive construction. However, the theory just sketched lacks an explanatory level. Without further amendments, alternative semantics fails to provide a theory of focus licensing. Such a theory should be able to explain what focus-sensitive constructions have in common and what kinds of semantic or pragmatic functions focus can serve. Rooth $(1992,1996)$ shows that such a theory can be developed in alternative semantics by building the restricting role of context on the interpretation of sentences with focused constituents into the system. In the following, we will briefly illustrate Rooth's theory of focus licensing. Note however that Rooth (1996) acknowledges that the arguments in favor of alternative semantics over other approaches to focus (such as structured meanings) are not conclusive.

In the framework introduced above, the meaning of a sentence with a focus marked constituent is determined by lexical meaning, syntax and the position of focus. However, this fails to capture the role of context in determining the set of alternatives. The assumption that alternatives are type-driven clearly over-generates. Focus-sensitive operators do not operate over the entire focus set, but rather over a contextually relevant set, as illustrated in (10) (Rooth 1996:279), where the set of propositions to which only applies consists of just three propositions:

(10) John brought Tom, Bill, and Harry to the party, but he only introduced Bill $l_{\mathrm{F}}$ to Sue.

The question then becomes how to constrain the set of alternatives to incorporate this context-dependence. Rooth proposes that for focus to be felicitous, the generated set of alternatives needs to be related to a denotation $\mathrm{C}$ in the near discourse. $\mathrm{C}$ consists of contextually available sets of alternatives and its value is determined by contextual or pragmatic information. Focus does not directly set the reference for C, but it does constrain it. Specifically, focus interpretation contributes constraints on the relation between $\mathrm{C}$ and the focus alternative set. One such condition holds that $\mathrm{C}$ should be a subset of the focus semantic value of a given sentence. Formally, Rooth assumes that such constraints are always introduced as presuppositions via the $\sim$ operator, the operator responsible for focus interpretation, as stated in (11) below (Rooth 1996:285)

(11) Where $\phi$ is a syntactic phrase and $C$ is a syntactically covert semantic variable $\phi \sim C$ introduces the presupposition that $C$ is a subset of $[[\phi]]^{\mathrm{f}}$ containing $[[\phi]]^{\circ}$ and at least one other element.

To give an example of how this operator handles focus licensing, let us consider the following question-answer pair: 
Q: Who saw Lisa?

A: [John $]_{\mathrm{F}}$ saw Lisa.

a. $\mathrm{C}=[$ Who saw Lisa?]

b. $\left[\mathrm{John}_{\mathrm{F}}\right.$ saw Lisa] $\sim \mathrm{C}$

c. $[\phi \sim \mathrm{C}]$ is felicitous if $\mathrm{C} \subseteq[[\phi]]^{\mathrm{f}}$

The denotation of the question in (12) is the set of propositions that qualify as answers (following Hamblin 1973, see section 1.1), i.e. the set of propositions \{that Paul saw Lisa, that John saw Lisa, that Linda saw Lisa, . . . . The focus value of the answer is identical - it contains propositions of the form $x$ saw Lisa, where $x$ is an individual (or a group of individuals). The $\sim$ operator requires that the meaning of the question is a subset of the focus semantic value of the answer (12c). Since this requirement is satisfied in (12), focus on John is licensed. If on the other hand, the question had been Who did John see?, denoting the set of propositions \{that John saw Lisa, that John saw Paul, that John saw Linda... \}, C wouldn't have been a subset of the focus value of the answer in (12) and so focus on John would not have been licensed.

In the case of a focus-sensitive operator like only, focus is licensed if the domain of quantification of only, namely $\mathrm{C}$, is a subset of the focus semantic value. The sentence in (9a) for example gets the following representation:

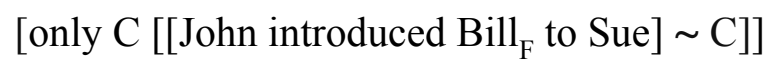

Once again, focus simply requires that $\mathrm{C}$, the set of contextually relevant alternatives with which only combines, is a subset of the focus semantic value of John introduced Bill $_{F}$ to Sue (consisting of propositions of the form John introduced $x$ to Sue). If this constraint is satisfied, only simply states that the assertion (and its entailments) is the only true proposition in C. This derives the appropriately restricted meaning for (10) above.

In the system just sketched, there is no construction-specific rule for the interpretation of focus. In each case, it is presupposed that there is some contextually relevant set of alternatives, independently available. For a wh-question, the relevant set is the denotation of the question, for an alternative question like Does Ede want coffee or tea, the set consists of the propositions Ede wants coffee and Ede wants tea, etc. If there is no such salient set of alternatives already in the context, accommodation comes in. This explains why focus is perceived as deviant in out of the blue contexts, such as (14a), but perfectly felicitous when the context supplies a suitable set of alternatives (14b):

a. Upon arriving at the tourist information office:

\# I want information on [hotels $]_{\mathrm{F}}$.

b. A: Do you need information on accommodation, transportation or activities?

B: I want information on [hotels $]_{\mathrm{F}}$.

This kind of contrast indicates that focus activates alternatives which need to be made sense of, a process in which context plays a crucial role.

It should be mentioned that the exhaustive inference derived in (12) and (13) above, whereby the denotation of the uttered sentence is the only one that is true out 
of the set of focus alternatives, can also surface in the absence of overt focus-sensitive expressions. Chierchia (to appear) provides the following example:

(15) Yesterday, John eventually decided to show up at the party. He walked in, grabbed a drink, greeted everybody, kissed Paul and Sue, and then left.

The sequence in (15) conveys that John only kissed Paul and Sue (among the guests), even in the absence of an overt only or even focal stress. As originally proposed in Groenendijk and Stokhof (1984), exhaustivity effects can be derived in terms of a phonologically null operator (akin to only). This operator can occur in a questionanswer pair like (12) or in statements such as (15), yielding an effect similar to overt focus.

Let us summarize the main components of the alternative-based approach to focus in the bi-dimensional set-up developed by Rooth. Focus is uniformly assumed to evoke alternatives, which are kept separate from ordinary semantic values. Alternatives are derived compositionally and are operated over by alternativesensitive operators like only or even (which can sometimes be covert). The relation between alternative sets and alternative sensitive operators is syntactically encoded (via the $\sim$ operator). This latter component of the theory constitutes an important move in alternative semantics insofar as it shows how a compositional treatment of alternatives can incorporate contextual restrictions. Rooth thus provides an explicit model of how to generate, compute and constrain alternatives.

However, this framework has been argued to have difficulties accounting for cases of multiple foci. Kratzer (1991) shows that alternative semantics fails to capture cases like the following:

$$
\text { I only went to }[\text { Tanglewood }]_{\mathrm{F}} \text { because you did. }
$$

Assuming that the elided VP in (16) is interpreted by copying the missing VP from the antecedent VP and deleting duplicated material, we obtain (17):

$$
\text { I only went to } \left.[\text { Tanglewood }]_{\mathrm{F}} \text { because you did [go to }[\text { Tanglewood }]_{\mathrm{F}}\right] \text {. }
$$

Intuitively, the sentence in (16) says that there is only one value of $\mathrm{X}$ that makes $I$ only went to $X$ because you went to $X$ true, namely the value where $\mathrm{X}=$ Tanglewood. Alternative semantics however produces different, incorrect interpretations. In particular, it allows the two foci to vary independently. This means that the set of alternatives could include any proposition of the form I only went to X because you went to $Y$, which would incorrectly predict (16) to allow the continuation I didn't go to Block Island because you went to Elk Lake Lodge. The dependency between the two focus values appears not be captured by the alternative-based mechanism introduced above (as discussed in detail in e.g. Kadmon 2001, Krifka 2006). Various solutions have been proposed in the literature, relying on focus indices and assignment functions (Kratzer 1991), a more general mechanism of structure-sharing (Sauerland 2007) or a dynamic treatment of ellipsis, which comes out as a special case of anaphora (Beaver and Clark 2008). Such amendments to the original theory make it possible to maintain that alternative semantics can adequately model focus sensitivity.

Analyses couched in a multi-dimensional alternative semantics have been explored for several phenomena, more or less directly connected with focus, such as 
topics (Büring 1997), intervention effects (e.g. Beck 1996, 2006; Kim 2002; Mayr 2010), polarity sensitivity (e.g. Krifka 1995; Lahiri 1998; Chierchia 2006, to appear; Crnič 2011) or implicature calculation, a topic discussed in detail in the next section.

\subsection{Implicatures}

The alternative-based accounts couched in either Hamblin- or Rooth-style semantics are mainly concerned with the use of alternatives, i.e. how alternatives combine in the course of semantic composition and how this determines the properties of various phenomena. Alternative sets are typically assumed to be semantically determined (mainly type-driven), with some kind of mechanism to prevent over-generation and incorporate contextual restrictions. With these assumptions in place, there has been little discussion on where alternatives come from and what exactly counts as a 'good' alternative (see however Cohen 1999 or Wagner 2010). The situation is very different in the study of implicatures, in particular scalar implicatures, an area of semantics and pragmatics where alternatives have received a lot of attention. Since implicatures rely on reasoning about alternatives, i.e. other things the speaker could have said, the reasoning can only go through if the 'right' alternatives are considered. In this context, it becomes important to explain how exactly alternatives are determined.

To illustrate, imagine the utterance in (18a) in a context where we discuss the number of bilinguals in the Basque Country:

a. Some of my students speak Basque.

b. All of my students speak Basque.

The use of the quantifier some in (18a) typically gives rise to the inference that not all students in the relevant context speak Basque. As is well-known since the seminal work of Grice (1975/1989), this inference comes about from reasoning about the intentions of the speaker and the motivation for uttering (18a), rather than some other, alternative utterance. A plausible informal reconstruction of the reasoning underlying the above-mentioned implicature goes as follows. The speaker chose to utter (18a) instead of (18b), which would have also been relevant. (18b) is more informative (i.e. asymmetrically entails (18a)). If the speaker had known that the sentence with all is true, she would have said so. On the assumption that the speaker is cooperative and has an opinion as to whether (18b) is true, this implies that the speaker takes (18b) to be false.

A crucial component in the reasoning just sketched is (18b), the alternative utterance to which the assertion is being compared. This raises two related questions: (i) what are the alternatives that are considered by the hearer and (ii) how do these alternatives relate to the assertion? Many factors determine what counts as a 'good' alternative. In the reasoning above, we used notions like relevance and informativity, which clearly play a key part in the calculation of the correct implicature. Consider the following sentences:

(19) a. Some of my students speak Basque and have blue eyes.

b. Some of my students speak Basque and some of my students don't speak Basque.

c. Some but not all of my students speak Basque.

d. Only some of my students speak Basque. 
Strictly speaking, the sentence in (19a) is more informative than (18a), but is not the alternative we are considering to derive the scalar implicature. A plausible reason is that (19a) is unlikely to be relevant in the context of a discussion about bilingualism, which would explain why we do not apply the reasoning illustrated for (18b). However, relevance considerations cannot exclude (19b-d) from the set of alternatives, for each one of these three sentences is more informative than the assertion and at least equally relevant. By the reasoning above, the hearer would be predicted to derive wrong implicatures. For instance, negating (19c) and adding this to the initial utterance yields Some of my students speak Basque and it is not the case that some but not all of my students speak Basque. This is equivalent to All of my students speak Basque, which in fact contradicts the actual implicature of (18a), clearly a wrong result. These simple examples demonstrate the importance of the right notion of alternatives in a theory of (scalar) implicatures. There is an extensive literature on implicatures, with lively debates on where, why and how exactly such inferences are derived (for recent reviews, see e.g. Sauerland 2012; Chierchia, Fox, and Spector 2012; Schlenker 2012). For our present purposes, we limit the discussion to the notion of alternative that is relevant for implicature calculation and review the various factors that have been argued to determine the correct alternatives.

These issues were not addressed by Grice, but they have been at the core of neo-Gricean approaches to implicatures (e.g. Horn 1972, 1984, 1989, Gazdar 1979, Atlas and Levinson 1981, Sauerland 2004, Geurts 2010, among many others). In particular, Horn (1972) introduces the notion of scales, i.e. more or less conventionalized sets of lexical items ordered by entailment, exemplified in (20) (Horn 1989: 232):

$$
\begin{aligned}
& \text { a. }<\text { all, most, many, some }> \\
& \text { b. }<\text { and, or }> \\
& \text { c. }<\text { must, should, may }> \\
& \text { d. }<\text { always, usually, often, sometimes }> \\
& \text { e. }<\ldots, 6,5,4,3,2,1> \\
& \text { f. }<\text { none, not all }> \\
& \text { g. }<\text { necessary, (logically) possible }> \\
& \text { h. }<\text { certain, \{probable/likely } \text {, possible }> \\
& \text { i. }<\text { boiling, hot, warm }> \\
& \text { j. }<\text { adore, love, like }>
\end{aligned}
$$

As these examples illustrate, scales are typically represented as ordered $n$-tuples of lexical items, with each element understood as entailing the elements to its right. $\mathrm{Or}$ and and are said to be scale-mates, where scale-mate-of is a symmetric relation. Once we adopt scales of this kind, known as quantitative or Horn scales, the alternatives to a sentence $S$ considered in the course of implicature calculation consist of the set of S', where S' is obtained by (possibly successive) replacement(s) of an expression with one of its scale-mates. ${ }^{2}$ If the derived alternative is stronger, the reasoning sketched above triggers a scalar implicature.

This straightforwardly captures the relation between (18a) and (18b) and provides an explanation for the absence of $(19 \mathrm{c})$ from the set of alternatives: some cannot compete with some but not all because they don't occur on the same scale. This result has been taken to support the existence of such lexically determined sets of alternatives. However, subsequent work has shown that the notion of scale as defined above needs further refinements (e.g. Fauconnier 1975, Gazdar 1979, Atlas and 
Levinson 1981, Hirschberg 1985, Matsumoto 1995, Israel 2011). More specifically, it has been pointed out that scale-mates need to be "of the same form class, in the same dialect or register, lexicalized to the same degree [...] and "about" the same semantic relations" (Levinson 2000:79). For example, the different degree of lexicalization prevents iff and if from being part of the same scale. Similarly, since regret introduces a semantic component (i.e. negative feeling or attitude) that is absent in know, the two factive verbs cannot be scale-mates. Moreover, Horn (1989) shows that scales are also subject to a monotonicity constraint: a scale cannot simultaneously include 'positive' (upward-entailing) and 'negative' (downward entailing) elements. Some and none for example cannot be scale-mates because positive and negative quantifiers belong to different scales. Yet, even once such additional factors are taken into account, the definition of scales in terms of semantic entailment remains too narrow. Fauconnier (1975) and Hirschberg (1985) discuss a variety of examples showing that actual entailments are not necessary for scalar implicatures. As illustrated by the examples in (21), some scales can be pragmatically established:

(21) a. A: Do they have any preschoolers in the program?

$\mathrm{B}$ : They have toddlers.

b. A: Is she married?

B: She's engaged.

c. A: Did John mail his application?

B: He wrote it.

d. A: Did you get Paul Newman's autograph?

B: I got Joanne Woodward's.

In each of these cases, there is an ordering relation that supports the kind of scalar reasoning involved in scalar implicatures which is not based on logical entailment. Hirschberg argues that the relations that define (possibly ad hoc) scales include only those relations that define partially ordered sets (POSETS). As long as speakers can create such a set, the scalar reasoning goes through. The classical Horn scales obviously fall under this heading, as a case where the ordering relation is entailment.

However, scale-based lexical replacements are not sufficient to derive all the necessary alternatives. This has been shown in particular for disjunction, in examples like the following:

John ate the apple or the pear.

The sentence gives rise to an exclusiveness inference, that John did not eat both the apple and the pear. Like before, this inference can be derived by assuming that the conjunction is a scale-mate of or. However, this assumption cannot derive the ignorance inference triggered by (22), namely that the speaker doesn't know which one of the disjuncts holds. Sauerland (2004) offers a solution to this problem by including in the set of alternatives not only the conjunction, but also each one of the disjuncts, i.e. John ate the apple and John ate the pear. This move however has been shown to be problematic insofar as it generates too many implicatures: if $p$ or $q$ has as its scale-mates $p$ and $q$, it follows that $p$ and $q$ are scale-mates of each other, regardless of what they are, a clearly undesirable result. Similarly, if $p$ has as its alternative $p$ or $q$, then not [p or $q]$ is an alternative of not $p$; asserting not $p$ should therefore trigger the inference that $p$ or $q$ is true (i.e. not [not $\left[\begin{array}{ll}p \text { or } & q\end{array}\right]$ ), which together with not $p$ implicates that $q$ is true (for details and further discussion see 
Sauerland 2004, Fox 2007 and Schlenker 2012).

In view of the problems mentioned above, there are recent attempts to develop a theory of alternatives that does not rely on scales. Katzir (2008), followed by Fox and Katzir (2011), proposes a syntactic procedure to compute alternatives, in which the possible replacements of a constituent is the set of all constituents that are at most equally complex. Specifically, the proposed procedure is defined as in (23) below (Fox and Katzir 2011:97):

(23) a. $S^{\prime}$ is an alternative of $S$ if $S^{\prime}$ can be derived from $S$ by successive replacements of sub-constituents of $S$ with elements of the substitution source for $S$ in C

b. The substitution source for $\mathrm{X}$ in a context $\mathrm{C}$ is the union of the following sets:

(i) The lexicon

(ii) The sub-constituents of $\mathrm{X}$

(iii) The set of salient constituents in $\mathrm{C}$

This more sophisticated algorithm, which makes no direct reference to the notion of scales, is argued to preserve the results of scale-based procedures and to derive the correct alternatives in more complex cases. In the case of disjunction for example, it is clear that $p$ is a member of the substitution source of $p$ or $q$; the reverse does not hold: there is no substitution operation which can derive $p$ or $q$ from $p$ (see Fox and Katzir 2011 for further details).

This brief overview of alternatives in the theory of implicatures suggests that there is no single decisive factor in determining the alternatives in a given context. A related point of contention in the literature is the computation of these alternatives (however obtained). Without getting into details, 'pragmatic' theories of implicatures (most recently defended in Geurts 2010) assume that these inferences arise from reasoning about why the speaker chose a particular utterance. Crucially, this reasoning can only take place at the level of complete utterances, which means that implicature calculation (and thus the consideration of alternatives) is a global, postcompositional phenomenon. In contrast to this, 'grammatical' theories of implicatures (most recently defended in Chierchia, Fox, and Spector 2012) assume that scalar implicatures can also be computed compositionally, and as such can arise at embedded levels. Consequently, on this approach, alternatives can be accessed and processed in the computational system of grammar (possibly via a covert exhaustification mechanism, similar to the one invoked for focus). This matter has been the subject of a lively and ongoing debate, with sophisticated empirical and conceptual arguments, which we cannot review here (see Sauerland 2012 for a recent overview of the existing approaches). The points discussed above should nevertheless suffice to establish the fact that a successful theory of implicatures cannot dispense with an explicit model of how to generate and compute alternatives.

\subsection{Main questions and open issues}

In the previous sections, we reviewed the use of alternatives in semantics and pragmatics by focusing on the three domains that arguably constitute the primary sources of alternative semantics: questions, focus and implicatures. In each case, we introduced the main assumptions concerning alternatives and the way in which they capture the phenomena under consideration, and we outlined some of the aspects that led to further adjustments. As previously noted, the notion of alternatives has been approached from different perspectives in the three areas of investigation we have 
examined. Whereas theories of implicatures focused on the appropriate relation among (mainly lexical) alternatives, the literature on focus and questions paid more attention to the compositional derivation of propositional alternatives. Going beyond these phenomena, there are three main questions emerging from the constantly expanding applications of alternative semantics, on the basis of which alternativebased theories can be distinguished: (i) the source of alternatives, (ii) the mechanism underlying the generation of propositional alternatives, and (iii) the relation between alternatives and the assertion.

The first concerns the source of alternatives. In the discussion above, we have seen that alternatives can be induced by certain lexical items, by focus or by context. Consider the sentences in (24) below:

a. Some students wrote to the dean.

b. Some students wrote to the DEAN.

In both cases, the speaker asserts that some students (in the relevant context of utterance) wrote to the dean. The enriched meaning is however different in each case, depending on the alternatives considered by the conversation participants. For example, in addition to the asserted meaning, the sentence in (24a) might communicate that not all students wrote to the dean, an inference derived by assuming that the use of the word some triggers the activation of its scale-mate all. If contextually relevant, (24a) could also implicate that only a small number of students wrote to the dean, i.e. It is not the case that most students wrote to the dean, an implicature that follows from the activation of the more fine-grained scale which includes some and most. Upon hearing (24a), it is also possible to infer that the students didn't meet with the dean, for example when used as an answer to the question Did anybody meet with the dean to talk about the strike?. On the other hand, the sentence in (24b) communicates that some students wrote to the dean, as opposed to, say, writing to the department chair. This interpretation is clearly due to the presence of focus on 'dean'. Examples of this kind illustrate how different sets of alternatives lead to different enriched meanings of a given sentence (and as such affect its felicity in a given context), despite the fact that the asserted meaning is identical. The question is what exactly triggers the relevant set of alternatives. In (24a), and analogous cases of scalar implicatures, it seems to be the use of a lexical item that belongs to a lexicalized scale (some) or to an ad hoc scale (getting in contact by writing to someone, as opposed to meeting in person). As mentioned in the discussion of scales in section 1.3, there is currently no consensus on where quantitative scales come from and what the principles governing the formation of (grammaticalized or ad hoc) scales are. Focus alternatives on the other hand are generally type-driven, i.e. the focused constituent determines the relevant set of alternatives, which are obtained by replacing the focused constituent with an element of the same semantic type (a procedure supplemented with some kind of mechanism to integrate the role of context). In the case of questions, alternatives come about in virtue of the presence of an interrogative word or operator (possibly covert), which plays a crucial part in deriving the set of propositions that constitutes the denotation of the question (regardless of the underlying mechanism, in situ or movement-based). The more general question is what are the possible sources of alternatives and what is the role of grammar and context in determining them.

A second and related question is how phrasal alternatives are determined. If certain items or constituents activate alternatives, how do these combine with the 
other constituents in the sentence to generate sets of propositional alternatives (accessed by alternative-sensitive operators)? At least three different mechanisms have been proposed in the literature: in situ, movement-based or structure-based systems. The first one assumes that the alternative-introducing element stays in situ and relies on special composition rules to combine sets. One such rule is the pointwise functional application illustrated in (3) above, whereby alternatives expand, i.e. give rise to alternatives of a higher type. This is the system employed in Hamblin (1973) and Rooth (1992) and much subsequent work in alternative semantics. Further developments of this mechanism led to the definition of other alternative-friendly rules of composition (e.g. the rule of Predicate abstraction in Kratzer and Shimoyama 2002, carefully discussed in Romero and Novel's contribution to this volume) or related in situ mechanisms (e.g. the system in Kratzer 1991, which relies on focus variables and dedicated assignment functions).

Another option, pursued mainly for the semantics of questions (following Karttunen 1977), and to a lesser extent for focus (e.g. Wagner 2005), is a movementbased system of generating alternatives. For illustration, consider a wh-question, where the resulting propositional alternatives only differ with respect to the value of the wh-word:

a. Which book did John read?

b. \{that John read The Magic Mountain, that John read The Brothers Karamazov, ...\}

In a Karttunen-style theory of questions, this interpretation is obtained by treating the wh-phrase as an existential quantifier and by assuming that it moves to adjoin to a socalled proto-question, i.e. the phrase headed by the interrogative operator ?. A simplified Logical Form for (25) looks as in (26a) and the resulting interpretation as in (26b):
a. [CP which book ${ }_{1}$ ? [IP John read $\left.\left.\mathrm{t}_{1}\right]\right]$
b. $\lambda$ p. $\exists x[\operatorname{book}(x) \& p=\operatorname{read}(\operatorname{John}, x)]$

The operation that turns declarative-type semantic values into interrogative-type semantic values (sets of propositions) hinges on the propositional variable $p$ over which lambda abstraction can take place. Crucially, the fronted $w h$-expression must be interpreted outside the scope of this variable (for discussion see e.g. Heim 2001). The assumption that wh-phrases move (together with the assumption that an interrogative operator is present in the structure) delivers the correct interpretation of the question, which on this approach amounts to the right set of propositions.

Sets of alternatives, in particular focus alternatives, have also been argued to obtain via a structure-based mechanism, which consists of a series of replacement operations (Fox 2000, Sauerland 2007, Katzir 2008, Fox and Katzir 2011). This view maintains a syntactic definition of alternatives, as opposed to lexically-driven or typedriven replacements of the alternative-introducing element. Essentially, alternatives are obtained by (series of) replacements, where each step replaces a focus-marked phrase with a phrase of the same syntactic category. This procedure has been argued to derive the dependency between elided constituents and their focus-marked antecedents and to avoid the problems raised by lexically determined scales (as discussed in section 1.3 above).

With the notable exception of Fox and Katzir (2011), who argue for a similar 
system of generating alternatives for implicature and focus effects, different mechanisms have been employed for different phenomena. Do we need all these mechanisms, with different alternative-generating procedures playing a role in different phenomena? Or could one of the proposed methods be used to uniformly derive phrasal alternatives, regardless of their sources?

The third main question that can differentiate alternative-based accounts concerns the way in which alternatives relate to the asserted meaning. In the case of questions, the denotation is identical to the set of propositions that qualify as answers, and as such, alternatives and 'asserted' (i.e. interrogative) meaning cannot be distinguished. In the case of focus alternatives, we saw that in the system developed by Rooth, the association is indirect, and is established via a focus-sensitive operator, which incorporates them into the ordinary meaning. Crucially, in this system, alternatives are kept separate from basic meanings, unlike in Hamblin semantics, where standard semantic values are uniformly equated to alternative sets. The alternatives responsible for scalar implicatures have also recently been argued to enter semantic composition. Just like in the case of focus, they are used by alternativesensitive (i.e. exhaustivity) operators. In alternative-based theories of questions and focus, alternatives are obligatorily computed. Implicatures on the other hand, and hence the alternatives on which they are based, are not obligatory. Alternatives are activated only if relevant in a given context and if their computation leads to meaning enrichment (a result obtained by excluding any alternative stronger than the assertion).

A recent trend in the literature seeks to unify the computation of alternatives involved in focus and implicatures. As mentioned above, the grammatical theory of implicatures attributes implicature calculation to a covert grammatical operator, with a semantics very similar to only, generally referred to as $E X H$ or $O$ (see Chierchia to appear and Schlenker 2012 for detailed discussions of the issues raised by the various exhaustivity operators proposed in the literature). The empirical motivation typically offered in favor of this mechanism comes from exhaustive interpretations that arise in the absence of an operator like only, such as (15) above or question-answer pairs (as originally discussed in Groenendijk and Stokhof 1984). If such an exhaustification mechanism can be shown to be available in the grammar, it is conceivable that it will operate in more than one construction (a line of thinking explicitly pursued in Fox and Katzir 2011). ${ }^{3}$ This opens the way for further extensions and raises the question of whether the different phenomena that have been treated in terms of alternatives should receive a unified analysis whereby alternative-induced meaning enrichment always comes about via an exhaustification procedure. There are however important open questions concerning exhaustivity operators and the corresponding exhaustification procedures. Among them, how is their insertion constrained? Is their insertion governed by a principle of Maximize Strength, whereby the application of EXH needs to increase informativity (as proposed in e.g. Chierchia to appear)? More generally, at what point in the derivation are alternatives considered and exploited to enrich the asserted meaning? What are the principles governing meaning enrichment that results from consideration of alternatives? Although we will not review this here, it should be mentioned that there is a growing body of experimental work which investigates the connections between these phenomena (see Chemla and Spector 2011, Chemla, Homer and Rothschild 2011 for recent references). The constantly evolving experimental techniques can deliver rich data and provide new insights that could adjudicate between different theoretical models, as well as evaluate the robustness of the relation between different phenomena. 
For presentational purposes, the three phenomena and the corresponding alternative-based systems were introduced separately, but there are clear connections between them. As noticed by Rooth himself (1992: 84) and often pointed out in subsequent work (e.g. Hagstrom 2003, Kratzer 2005, Szabolcsi, Wang and Zu 2012), the set of focus alternatives is very similar to Hamblin's set of possible answers to the corresponding question. The Hamblin denotation of a question like Who saw Lisa? is the set of propositions of the form $x$ saw Lisa, just like the focus meanings of a sentence like $J_{O H N}$ saw Lisa, in (8) above. Moreover, alternatives are built and expanded in the same way, through pointwise functional application. For this reason, compositionally derived alternative sets are often referred to as Rooth/Hamblinalternatives. However, there are fundamental differences between the two systems. First, as previously mentioned, the relation between alternatives and ordinary semantic values. Hamblin's framework is 'one-dimensional', in the sense that ordinary semantic values are sets of alternatives. In contrast to this, in the multidimensional setting developed by Rooth, alternatives are kept separate from standard meanings: whenever active, alternative sets are computed separately from regular denotations, and factored into meaning by alternative-sensitive operators. In the former system, an indefinite like a man is interpreted as the set of individuals that are men, whereas in the latter system, it denotes an existential quantifier, and reference to a set of (relevant) individuals is only made in case alternatives need to be computed (for instance because of the presence of focus). The redefinition of semantic values in terms of sets has been argued to raise non-trivial technical questions. In particular, the semantic composition in Hamblin's system has been shown to run into problems in cases where sets of alternatives combine with movement and variable binding (Shan 2004, Romero and Novel this volume).

A related, and perhaps more important difference concerns the operators that access the sets of alternatives: unlike in the Hamblin semantics approach where (sets of) alternatives can be selected by various operators (e.g. quantificational, interrogative), in multi-dimensional approaches, alternatives are only used by focus sensitive operators, such as only or even (and possibly their covert counterparts), i.e. they are not visible to quantificational operators (see however Aloni 2007 for a definition of alternative-sensitive modals). To my knowledge, at this stage there are no empirical arguments in the literature that could decide between these two systems (see the discussion in Chierchia to appear). More generally, any alternative-based system has to define and motivate an inventory of alternative-sensitive operators and their properties. Can an operator operate over various sets of alternatives, and if so, under what conditions? If there is more than one operator in a given configuration, how do the various operators interact? A related question is how do different kinds of alternatives (for instance scalar and focus alternatives) interact? Whereas many of these issues are a matter of empirical investigation, any alternative-based system should in principle be able to predict attested and unattested configurations with one or several operators and alternative sets. Many of the studies cited above assume that alternatives and alternative-sensitive operators can be used to capture and predict cross-linguistic variation in certain areas. The success of this enterprise, and the comparison between alternative-based systems, depends to a large extent on the answers to these and related questions.

The proliferation of alternative-based accounts indicates that alternatives have become semantic/pragmatic objects, with designated rules of composition and interpretation and a delimited set of operators that can access them. However, for most phenomena mentioned above, one can also find proposals that do not employ 
alternatives. This raises the question of the empirical gain of using alternatives. A proper answer to this question would involve a detailed comparison of the empirical coverage and predictions of alternative- and non-alternative-based approaches to a given phenomenon and the benefits of resorting to alternatives might very well vary across phenomena. There are however certain domains where the use of alternatives has led to substantial progress. Among them, polarity and free choice indefinites, for which a wide array of alternative-based proposals have been developed (e.g. Fauconnier 1975, Kadmon and Landman 1993, Krifka 1995, Lahiri 1998, Lee and Horn 1994, Giannakidou 2001, Kratzer and Shimoyama 2002, Farkas 2002, 2006, Dayal 2004, Aloni and van Rooij 2005, Aloni 2007, Chierchia 2006, to appear, among many others). Taken together, these studies offer extensive evidence that the properties of many polarity sensitive indefinites follow to a large extent from the set(s) of activated alternatives and the way they are factored into meaning. The advantages of alternative-based accounts for (at least certain classes of) polarity sensitive items are by now relatively uncontroversial (see however Giannakidou and Quer 2011 for some skepticism). Chierchia (to appear), building mainly on Krifka (1995) and Kratzer and Shimoyama (2002), pursues the more ambitious goal of showing that all patterns of polarity can be captured in a multi-dimensional alternatives-and-exhaustification framework, which is furthermore assumed to be responsible for implicature calculation. Variation in the polarity system is captured through a highly restricted number of parametrical choices, along two interconnected dimensions: (i) types of active alternatives and (ii) modes of exhaustification. Whether such a strongly unitary approach ultimately succeeds in capturing the attested diversity of polarity patterns remains a matter of empirical investigation. What is perhaps more important at this stage is the fact that the use of alternatives has facilitated the pursuit of this program.

A related open issue concerns the possible advantages of generalizing alternative semantics to such a wide range of constructions. The conceptual appeal is obvious: if alternatives can be shown to do the work in one domain, it is tempting to exploit a similar mechanism elsewhere. The risk however is to take alternatives for granted and thus ignore the fact that there is currently no full-fledged theory of the source of alternatives or any prevailing view of how they should be computed. As alternative semantics keeps expanding, it is useful to bear these unresolved issues in mind in order to appreciate and compare the results of alternative-based theories.

\section{CONTENTS OF THE VOLUME}

The papers assembled in this volume share the assumption that alternatives provide a useful tool to account for certain linguistic phenomena and carefully explore its consequences. The first three chapters are directly concerned with implicature-based approaches to elements that give rise to ignorance or indifference inferences, such as disjunction or indefinite determiners like Spanish algún, German irgendein or English any.

Alonso-Ovalle and Menéndez-Benito examine the status of the ignorance inference triggered by the use of determiners like algún, illustrated in (27) below:

(27) María se casó con algún médico, \# en concreto con el doctor Smith. Maria SE married with ALGÚN doctor namely with the doctor Smith 'Maria married some doctor, namely doctor Smith' 
Since Kratzer and Shimoyama (2002), this component has often been analyzed as a quantity implicature, based on a competition between the assertion and a number of alternative propositions that correspond to different domains of quantification. This view has recently been challenged, in particular in work due to Aloni and Port, who argue that the inference should not be derived as an implicature. Alonso-Ovalle and Menéndez-Benito present further evidence against an implicature-based account, by arguing that the alternatives responsible for the ignorance effect are not sensitive to relevance, unlike what is known to be case for run-of-the mill implicatures, which are only drawn if contextually relevant. The authors further suggest a way to maintain the implicature approach, by proposing to factor in a pragmatic competition with other members of the paradigm, namely the plain indefinite determiner un. More generally, the facts discussed in this chapter emphasize the importance of a precise mechanism that determines what counts as an alternative.

Chierchia's contribution can be viewed as defending the opposite theory, namely that all ignorance (and indifference) effects triggered by existential elements (such as indefinite determiners or disjunction) should be derived as implicatures. The starting point is the similarity of the free choice effects in (28) below:

(28) a. You can have ice cream or cake.

a'. Each of the ice cream and the cake constitutes a legitimate choice.

b. You may have any cake.

b'. Each of the cakes constitutes a legitimate choice.

Examining their behavior in modal and downward-entailing contexts, the paper argues for the unitary character of free choice disjunction (FCD) and morphologically marked free choice items (FCIs), like German irgendein, and offers a uniform, alternative-based theory of the two phenomena. Two main theses are defended: (i) that a unified account (of FCD and FCIs) is necessary (in view of their empirical similarities) and (ii) that a principled unified account is, in fact, possible, by making use of alternatives. More specifically, FCIs and FCD are assumed to activate the same sets of alternatives, which are of two types: scalar alternatives (corresponding to a conjunction) and domain alternatives (consisting of subdomains of the relevant set of individuals in the case of FCIs and each one of the disjuncts in the case of FCD). The observed inferences are argued to uniformly arise through recursive exhaustification of these sets of alternatives. To capture the absence of free choice effects with disjunction in plain, non-modal contexts (such as John or Mary will show up), Chierchia argues that the alternatives activated by disjunction (or plain indefinites like $a$ or some) are in some sense optional, i.e. their use is subject to relevance. With FCIs on the other hand, alternatives are obligatorily factored into meaning (like focus alternatives), which explains why these items have a narrower distribution. The optional vs. obligatory activation of alternatives captures the differences between the two phenomena, thus enabling a uniform account of free choice effects, obtained on the basis of identical sets of alternatives, computed via an identical exhaustification mechanism.

In the chapter A Viability Constraint on Alternatives for Free Choice, Dayal adopts the framework developed by Chierchia and the assumption that FCIs are indefinites with a universal free choice implicature. However, she argues that the distributional restrictions displayed by FCIs should not be explained as a clash resulting from exhaustification over scalar and domain alternatives (as in Chierchia's work), but rather as following from a viability constraint on alternatives, which 
essentially requires a plurality of worlds over which alternatives can be distributed. This idea is exploited to capture a wide array of properties of FCIs, such as the distribution of partitive, non-partitive and numeral any (i.e. any one student) in episodic, modal and subtrigged contexts. Moreover, this constraint is taken as a basis to show the need for more refined empirical generalization regarding the distribution of FCIs in imperatives. More concretely, Dayal shows that imperatives do not license FCIs as easily as commonly assumed and discusses the role of contextual factors in satisfying the posited viability constraint on alternatives.

The following three chapters refine existing alternative-based proposals either by employing alternatives to capture new empirical facts or by proposing solutions to previously noticed problems raised by the use of alternatives.

Mayr's paper compares two recent approaches to intervention effects in whquestions that both make crucial use of an alternative-based semantics: Beck (2006) and Kratzer and Shimoyama (2002), on the one hand, and Mayr (2012), on the other. As well-known, focus operators intervening between two wh-elements result in ungrammaticality (29):

a. *Welche Frau hat nur der HANS wohin eingeladen? which woman has only the Hans where.to invited

b. Welche Frau hat wohin nur der HANS eingeladen? which woman has where.to only the Hans invited 'Which woman did only Hans invite where?'

Similar effects have been identified with negative or universal quantifiers, although in a less systematic way. Beck (2006), much in the spirit of Kratzer and Shimoyama (2002), argues that intervention effects follow from the way in which alternatives are computed. More precisely, they can be captured by assuming that wh-elements contribute semantic alternatives to the computation in a way similar to focus. Essentially, the intervening focus (or quantificational) operator 'consumes' the alternatives introduced by the $w h$-element, leaving the interrogative operator without any alternatives on which to operate. Mayr argues that alternatives are essential in order to predict the correct set of interveners but shows that alternative semantics per $s e$ does not derive intervention effects. Specifically, he presents evidence that the focus-based generalization cannot capture the behavior of quantifiers with respect to intervention effects (in particular the fact that upward-entailing quantifiers are not interveners). To account for the more refined empirical generalization introduced in this and related work (Mayr 2012), the author argues in favor of a bi-dimensional alternative-based semantics where $w h$ - and focus alternatives are kept separate.

Coppock and Beaver's paper offers a unified analysis of the exclusives mere and only. The authors analyze both mere and only in terms of questions under discussion modeled as structures defined over sets of alternatives, where the alternatives are non-standard in two respects. First, by analyzing predicative uses of mere, they show that there are free variables in the alternatives. Second, the consideration of exclusives indicates that alternatives can be ranked by relations other than entailment; in this sense, both mere and only are scalar both in their positive component ("at least X") and in their negative component ("at most X"). With evidence from negation, reason clauses, and emotive factive predicates, it is furthermore argued that the negative component of mere contributes to the at-issue meaning, while the positive component is presupposed, as has been previously argued for only. Taken together, the presence of unbounded variables in the alternatives and 
the fact that exclusives can introduce presuppositional constraints on the salient set of alternatives are taken to motivate a more dynamic semantics for exclusives (as proposed in Coppock and Beaver 2011).

The compositional interpretation of structures that contain both sets of alternatives and variables is also addressed in Romero and Novel's chapter. The starting point is the common assumption that languages contain structures whose semantic interpretation requires, at the same time, binding of variables via assignment functions (for pronoun and traces) and sets of alternatives (e.g. for indeterminate phrases in Japanese, free choice items, focus). This view was challenged in Shan (2004), where it is argued that compositional problems arise as soon as variable binding via assignments combines with sets of alternatives. Romero and Novel critically examine and propose solutions to the following three problems presented by Shan (i) over-generation of functional and pair-list readings in questions like Who saw nobody?; (ii) incorrect results when an XP binds into the "generator" of the set of

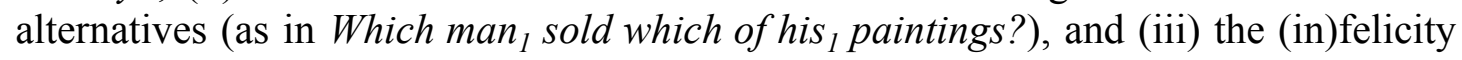
of more complex examples involving the aforementioned binding relation (the distinction between Every man $_{1}$ knows which painting of his $s_{1}$ is good and Every man ${ }_{1}$

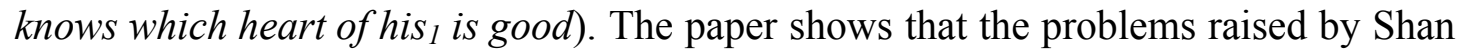
can be circumvented, thus indicating that alternative semantics can successfully combine with movement and the binding of variables.

The final two chapters of the volume present experimental studies that confirm the role of contextual, syntactic or semantic factors in determining the correct set of alternatives.

Panizza and Romoli's paper focuses on the linguistic behavior and on-line processing of the Italian word mai, an item that exhibits typical properties of Negative Polarity Items (NPIs) on the one hand and of Negative-words (N-words) on the other. More precisely, like NPIs, mai exhibits sensitivity to the entailment properties of the sentence in which it occurs, but like N-words, mai gives rise to different meanings depending on its position with respect to the verb. The authors propose an alternative-based analysis of mai as an NPI with the additional capacity of introducing a covert negation in certain environments in pre-verbal position. The main goal is to investigate, through the case study of mai, the on-line processing of the theoretical mechanisms that are argued to be involved in its semantics, such as alternatives, exhaustification and insertion of covert negation. To this end, the authors make explicit hypotheses on how such mechanisms are connected to on-line processing, and test these hypotheses using the event related potential (ERP) methodology. The results indicate that during on-line processing, all sentences with mai, regardless of its position, are interpreted with obligatory exhaustification of the alternatives introduced by mai. If the result of exhaustification is not contradictory, mai retains its non-negative interpretation. If the result is contradictory, a reanalysis of the sentence is attempted, by inserting a covert negation to rescue the contradictory meaning arising from exhaustification of alternatives. The authors conclude that semantic properties of the context of occurrence - namely entailment patterns - play an important role in on-line processing of polarity sensitive items such as mai. Similar conclusions have been reached for the computation of scalar implicatures, also sensitive to entailment (Panizza, Chierchia and Clifton 2009), raising the question of whether the two phenomena rely on a similar mechanism.

The volume closes with Bale and Barner's study on Grammatical Alternatives and Pragmatic Development, which relies on evidence from language acquisition to address the nature of pragmatic inference, and the role of grammatical alternatives in 
scalar implicatures. Previous studies suggest that children have difficulty computing simple scalar implicatures. Paradoxically, many children who are unable to compute scalar implicatures have no difficulty with similar pragmatic inferences, such as those involved in learning new words, or in reasoning about the knowledge states of other individuals. This raises the question: why are children so successful with some forms of pragmatic inference, but not with others? To answer this question, the authors investigate the specific processes involved in scalar implicature and compare them to those involved in word learning and other pragmatic tasks. Although these types of inference share many common elements, they differ in one crucial respect: the generation of alternatives. The present work, combined with past studies, suggests that children's ability to compute pragmatic inferences differs depending on their familiarity with particular scales (i.e., the words or phrases that count as scalar alternatives). Children readily compute inferences for nouns and number words, but fail at very similar inferences that involve quantifiers and other types of functionwords (e.g., coordinators, modals, etc.). Furthermore, children easily compute implicatures when alternatives are provided explicitly by the context. Such evidence demonstrates that children possess sophisticated pragmatic abilities, but their ability to express such knowledge depends on access to grammatically determined sets of scalar alternatives (as originally proposed by Horn 1972). To compute quantity implicatures children must not only know the meanings of words like some and all, but they must learn that such words are related to one another as scalar alternatives. These data rule out the possibility that scales emerge automatically from the semantics of their members, and suggest that scales are not only grammatical in nature, but that they must associate with one another gradually over acquisition.

Without exhausting the range of conceptual, theoretical and empirical issues raised by alternatives, the variety of alternative-based systems as well as the diversity of empirical phenomena addressed in this volume demonstrate the vitality of alternative-based semantics and offer clearer perspective on the many challenging questions that arise from its increasing range of applications. 


\section{Acknowledgements}

I wish to thank Uli Sauerland for valuable comments and suggestions on an earlier draft of this introduction. I am also grateful to the participants at the Workshop on alternative-based semantics held in October 2010 in Nantes for discussion of some of the issues presented here. All errors and omissions are mine.

\section{Notes}

${ }^{1}$ Well-known examples include the development of Binding Theory (e.g. Reinhart 1983, Fox 2000, Büring 2005, Reinhart 2006, Heim 2007 among many others), economy considerations involved in various types of movement, such as quantifier raising or wh-movement (e.g. Fox 2000, Reinhart 2006; see Müller and Sternefeld 2000 for an overview of competition in syntax), the interpretation of reciprocals and plural predicates, regulated by the Strongest Meaning Hypothesis (e.g. Dalrymple et al. 1994, Winter 2001), or frameworks such as Optimality Theory (e.g. Prince and Smolensky 1993, Hendriks and de Hoop 1997).

${ }^{2}$ Whether the scalar item is replaced with the next weaker or the next stronger item on its scale depends on the context: as is well-known, the consideration of stronger items gives rise to scalar implicatures in upward-entailing contexts only; in downward-entailing contexts a stronger assertion obtains by replacing the scalar item with a weaker scale-mate. In other words, what matters is the entailment relation between the sentences obtained by substituting scalar items, not the relation between the scalar items themselves (see Sauerland 2004).

${ }^{3}$ Similar questions are addressed in an alternative-based framework which we haven't mentioned so far, namely inquisitive semantics (e.g. Groenendijk and Roelofsen 2009, Ciardelli, Groenendijk and Roelofsen 2012). The approach seeks to redefine semantic meaning so as to capture not only informative (standard) meaning, but also inquisitive meaning (reflecting the interactive use of language in exchanging information). In this framework, unitary accounts have been proposed for questions and disjunctions, both of which raise an issue by presenting a set of alternatives and demanding that one of them be chosen. 


\section{References}

Aloni, M. and R. van Rooij (2007) 'Free Choice Items and Alternatives' in G. Bouma, I. Kraemer, and J. Zwarts (eds.) Cognitive Foundations of Interpretation (Edita KNAW).

Alonso-Ovalle, L. (2006) Disjunction in alternative semantics. PhD. dissertation, University of Massachusetts at Amherst.

Alonso-Ovalle, L. and P. Menéndez-Benito (2010) 'Modal Indefinites', Natural Language Semantics, 18(1): 1-31.

Arregui, A. (2006) 'Cualquier, exception phrases and negation' in J. Doetjes and P. Gonzalez (eds.) Romance languages and linguistic theory (Amsterdam: Benjamins), pp. 1-22.

Atlas, J. (1993) 'The Importance of Being "Only": Testing the Neo-Gricean Versus Neo-entailment Paradigms', Journal of Semantics, 10:301--318.

Atlas, J. D., and S. Levinson (1981) 'It-clefts, informativeness and logical form: Radical pragmatics (revised standard version)' in P. Cole (ed.) Radical Pragmatics (New York: Academic Press), pp. 1-62.

Beaver, D. and B. Clark (2008) Sense and Sensitivity: How Focus Determines Meaning (Oxford: Blackwell).

Beck, S. (1996) Wh-constructions and Transparent Logical Form, PhD dissertation, Universität Tübingen.

Beck, S. (2006) 'Intervention effects follow from focus interpretation', Natural Language Semantics, 14:1-56.

Büring, D. (1997) The Meaning of Topic and Focus-The 59th Street Bridge Accent (London: Routledge)

Büring, D. (2005) Binding Theory (Cambridge: Cambridge University Press)

Ciardelli, I., J. Groenendijk, and F. Roelofsen (2012) 'Inquisitive semantics: a new notion of meaning', to appear in Language and Linguistics Compass.

Chemla, E. and B. Spector (2011) 'Experimental evidence for embedded scalar Implicatures', to appear in Journal of Semantics.

Chemla, E., V. Homer, and D. Rothschild (2011) 'Modularity and Intuitions in Formal Semantics: The Case of Polarity Items', Linguistics and Philosophy 34(6): 537-570.

Chierchia, G. (2004) 'Scalar Implicatures, Polarity Phenomena, and the Syntax/Pragmatics Interface' in A. Belletti (ed.) Structures and Beyond (Oxford University Press), pp. 39-103.

Chierchia, G. (2006) 'Broaden your Views. Implicatures of Domain Widening and the Spontaneous Logicality of Language', Linguistic Inquiry, 37(4): 535-590.

Chierchia, G. (to appear) Logic in Grammar: Polarity, Free Choice, and Intervention; to appear with Oxford University Press

Chierchia, G., D. Fox, and B. Spector (2012) 'The grammatical view of scalar implicatures and the relationship between semantics and pragmatics' in $\mathrm{P}$. Portner, C. Maienborn and K. von Heusinger (eds.), Semantics: An International Handbook of Natural Language Meaning (Berlin: Mouton de Gruyter).

Cohen, A. (1999) 'How are alternatives computed?', Journal of Semantics, 16:43-65.

Coppock, E. and D. Beaver (2011) 'Sole sisters'. In Ashton, N., A. Chereches, A., and D. Lutz (eds.), Proceedings of the 21st Semantics and Linguistic Theory Conference (Rutgers University: eLanguage)

Crnič, L. (2011) Getting even, $\mathrm{PhD}$ dissertation, MIT. 
Dayal, V. (1998) 'Any as Inherently Modal', Linguistics and Philosophy, 21: 433-476.

Dayal, V. (2004) 'The Universal Force of Free Choice Any', Linguistic Variation Yearbook, 4: 5-40.

Dalrymple, M., M. Kanazawa, Y. Kim, S. Mchombo, and S. Peters (1998). 'Reciprocal expressions and the concept of reciprocity'. Linguistics and Philosophy 21:159-210.

Farkas, D. (2002) 'Varieties of indefinites' in Proceedings from SALT XII (Ithaca, NY: Cornell University), pp. 59-83.

Farkas, D. (2006) 'Free Choice in Romanian' in B. Birner and G. Ward (eds.) Drawing the Boundaries of Meaning (Amsterdam: John Benjamins), pp. 71-95.

Fauconnier, G. (1975) 'Polarity and the scale principle', Papers from the 11th regional meeting of the Chicago Linguistic Society (Chicago: Chicago Linguistic Society), pp. 188-199.

Fox, D. (2000) Economy and semantic interpretation (Cambridge, MA: MIT Press)

Fox, D. (2007) 'Free Choice Disjunction and the Theory of Scalar Implicatures', in U. Sauerland and P. Stateva (eds.) Presupposition and Implicature in Compositional Semantics (Houndmills: Palgrave Macmillan).

Fox, D. and R. Katzir (2011) 'On the Characterization of Alternatives', Natural Language Semantics, 19: 87-107.

Gazdar, G. (1979) Pragmatics: Implicature, Presupposition and Logical Form (New York: Academic Press).

Geurts, B. (2010) Quantity Implicatures (Cambridge: Cambridge University Press).

Giannakidou, A. (2001) 'The Meaning of Free Choice', Linguistics and Philosophy, 24.6: $659-735$.

Giannakidou, A. and J. Quer (2011) 'Against universal free choice: free choice and referentially vague indefinites in Greek, Catalan, and Spanish', Ms.

Grice, P. (1975/1989) Studies in the Way of Words (Harvard: Harvard University Press).

Groenendijk, J. and M. Stokhof (1984) Studies in the Semantics of Questions and the Pragmatics of Answers (Amsterdam: Akademish Proefschrift).

Groenendijk, J. and F. Roelofsen (2009) 'Inquisitive Semantics and Pragmatics', Language, Communication and Rational Agency, Stanford, USA, May 30-31, 2009.

Hagstrom, P. (1998) Decomposing Questions. Ph.D. dissertation, MIT.

Hagstrom, P. (2003) 'What questions mean', Glot International, 7:188-201.

Hamblin, C. (1973) 'Questions in Montague English', Foundations of Language, 10: 41-53.

Haspelmath, M. (1997) Indefinite Pronouns (Oxford: Oxford University Press)

Heim, I. (2007) 'Forks in the Road to Rule I' in M. Abdurrahman, A. Schardl, M. Walkow (eds.), Proceedings of the 38th Annual meeting of the North East Linguistic Society, pp. $256-284$.

Hendriks, P. and H. de Hoop (1999) 'Optimality theoretic semantics'. Ms., University of Groningen. (Cognitive Science and Engineering Prepublications 98-3)

Hinterwimmer, S. (2011) 'Information structure and Truth-Conditional Semantics' in P. Portner, C. Maienborn and K. von Heusinger (eds.), Semantics: An International Handbook of Natural Language Meaning, Vol. 2, (Berlin: Mouton de Gruyter), pp. 1875-1908

Hirschberg, J. (1985) A theory of scalar implicature, Doctoral dissertation, University of Pennsylvania, Philadelphia, PA 
Horn, L. (1972) On the semantic properties of the logical operators in English, Doctoral dissertation. UCLA Distributed by IULC, Indiana University.

Horn, L. (1984). 'Toward a new taxonomy for pragmatic inference: Q-based and Rbased implicature' in D. Schiffrin (ed.), Meaning, Form, and Use in Context: Linguistic Applications (Washington: Georgetown University Press), pp. 11-42.

Horn, L. (1989) A natural history of negation (Chicago: University of Chicago Press)

Israel, M. (2011) The Grammar of Polarity. Pragmatics, Sensitivity, and the Logic of Scales (Cambridge: Cambridge University Press).

Jayez, J. and L. Tovena (2005) 'Free Choice and Non-Individuation', Linguistics and Philosophy, 28:1-71

Kadmon, N. (2001) Formal Pragmatics: Semantics, Pragmatics, Presupposition and Focus (Oxford: Blackwell)

Kadmon, N. and F. Landman (1993) 'Any', Linguistics and Philosophy, 15: 353-422.

Karttunen, L. (1977) 'Syntax and semantics of questions', Linguistics and Philosophy $1(1), 3-44$.

Katzir, R. (2008) 'Structurally-defined alternatives', Linguistics and Philosophy, 30, 669-690.

Keshet, E. (2006) 'Scalar Implicatures with Alternative Semantics' in M. Gibson and J. Howell (eds.) Proceedings of SALT XVI (Cornell University, Ithaca: CLC Publications), pp. 88-101.

Kim, S.-S. (2002) 'Intervention effects are focus effects' in N. Akatsuka and S. Strauss (eds.) Japanese/Korean Linguistics, Vol. 10, (Stanford:CSLI), pp. 615628.

Kratzer, A. (1991) 'The Representation of Focus' in A. von Stechow and D. Wunderlich (eds.) Semantik: an International Handbook of Contemporary Research (Berlin: Walter de Gruyter), pp. 825-834.

Kratzer, A. (2005) 'Indefinites and the Operators they Depend On: From Japanese to Salish' in G. N. Carlson and F.J. Pelletier (eds.) Reference and Quantification: The Partee Effect (Stanford: CSLI), 113-142.

Kratzer, A. and J. Shimoyama (2002) 'Indeterminate Pronouns: The View from Japanese' in Y. Otsu (ed.) Proceedings of the Third Tokyo Conference on Psycholinguistics (Tokyo: Hituzi Syobo), pp. 1-25.

Krifka, M. (1992) 'A compositional semantics for multiple focus constructions', Linguistische Berichte 17-53.

Krifka, M. (1995) 'The Semantics and Pragmatics of Polarity Items', Linguistic Analysis, 25: 209-257.

Krifka, M. (2006) 'Association with Focus Phrases' in V. Molnar and S. Winkler, (eds.), The Architecture of Focus (Berlin, New York: Mouton de Gruyter), pp. 105-136.

Krifka, M. (2011) 'Questions' in P. Portner, C. Maienborn and K. von Heusinger (eds.), Semantics: An International Handbook of Natural Language Meaning, Vol. 2, (Berlin: Mouton de Gruyter), pp. 1742-1785.

Kuroda, S. - Y. (1965) Generative Grammatical Studies in The Japanese Language. Ph.D. Dissertation, MIT.

Jackendoff, R. (1972) Semantic Interpretation in Generative Grammar (Cambridge, MA: MIT Press)

Lahiri, U. (1998) 'Focus and Negative Polarity in Hindi', Natural Language Semantics, 6:57-125.

Lahiri, U. (2002) Questions and Answers in Embedded Contexts (Oxford: Oxford University Press) 
Lee, Y.-S. and L. Horn (1994) 'Any as indefinite plus even', ms., Yale University.

Levinson, S. (1983) Pragmatics (Cambridge: Cambridge University Press).

Levinson, S. (2000) Presumptive Meanings (Cambridge: MIT Press).

Matsumoto, Y. (1995) 'The conversational condition on Horn Scales', Linguistics and Philosophy, 18:21-60.

Mayr, C. (2010) The role of alternatives and strength in grammar, $\mathrm{PhD}$. dissertation, Harvard University.

Menéndez-Benito, P. (2005) The Grammar of Choice. PhD. dissertation, University of Massachusetts at Amherst.

Morzycki, M. (2010) 'Metalinguistic comparison in an alternative semantics for imprecision', Natural Language Semantics, 19: 39-86.

Müller, G. and W. Sternefeld (2000) 'The Rise of Competition in Syntax: A Synopsis' in G. Müller and W. Sternefeld (eds.), Competition in Syntax (Berlin: Mouton de Gruyter), pp. 1-68.

Murray, S. (2009) 'A Hamblin semantics for evidentials' in E. Cormany and S. Ito (eds.) Proceedings of SALT 19, eLanguage, pp. 324-341.

Panizza, D., Chierchia, G. \& Clifton, C., Jr. (2009) 'On the role of entailing patterns in the interpretation and processing of numerals and scalar quantifiers', Journal of Memory and Language, 61: 503-518.

Prince, A. and P. Smolensky (1993) Optimality Theory: Constraint Interaction in Generative Grammar (Cambridge, MA: MIT Press)

Ramchand, G. (1997) 'Questions, Polarity, and Alternative Semantics' in Proceedings of NELS 27 (Amherst: GLSA), pp. 383-396.

Rawlins, K. (2008) (Un)conditionals: an investigation in the syntax and semantics of conditional structures, $\mathrm{PhD}$ dissertation, UCSC.

Reinhart, T. (1983) Anaphora and Semantic Interpretation (London: Croom Helm)

Reinhart, T. (2006) Interface Strategies (Cambridge, MA: MIT Press)

Rooth, M. (1985) Association with Focus. Ph.D. dissertation, University of Massachusetts at Amherst.

Rooth, M. (1992) 'A Theory of Focus Interpretation', Natural Language Semantics, $1(1): 75-117$.

Rooth, M. (1996) 'Focus' in S. Lappin (ed.) The Handbook of Contemporary Semantic Theory (Oxford: Blackwell), pp. 271-297.

Sauerland, U. (2004) 'Scalar Implicatures in Complex Sentences', Linguistics and Philosophy, 27: 367-391.

Sauerland, U. (2007) 'Copying vs. structure sharing: A semantic argument', Linguistic Variation Yearbook, 7: 27-51.

Sauerland, U. (2012) 'The Computation of Scalar Implicatures: Pragmatic, Lexical, or Grammatical?', Language and Linguistics Compass, 6.1: 36-49.

Schlenker, P. (2012) 'The Semantics/Pragmatics Interface', ms, final version to appear in M. Aloni and P. Dekker (eds.). Handbook of Semantics.

Shan, C. (2004) 'Binding alongside Hamblin alternatives calls for variable-free semantics' in R. B. Young (ed.), Proceedings of SALT XIV (Ithaca, NY: CLC Publications), pp. 289-304.

Shimoyama, J. (2001) Wh-constructions in Japanese, Ph.D. dissertation, University of Massachusetts at Amherst.

Shimoyama, J. (2006) 'Indeterminate phrase quantification in Japanese', Natural Language Semantics, 14:139-173.

von Stechow, A. (1989) 'Focusing and background operators' in W. Araba (ed.) Discourse Particles (Amsterdam:John Benjamins), pp 37-84. 
von Stechow, A. (1991) 'Current Issues in the Theory of Focus' in A. von Stechow and D. Wunderlich (eds.) Semantik: an International Handbook of Contemporary Research (Berlin: Walter de Gruyter), pp. 804-825.

Szabolcsi, A., J. D. Whang, and V. Zu (2012) 'Compositionality questions: quantifier words and their multi- functional(?) parts', ms, NYU.

Wagner, M. (2005) 'NPI-Licensing and Focus Movement' In E. Georgala and J. Howell (eds.) Proceedings of SALT XV (Ithaca, NY: CLC Publications), pp. 276-293.

Wagner, M. (2010) 'Focus and Givenness: A Unified Approach' in I. Kučerová and A. Neeleman (eds.) Information Structure. Contrasts and Positions (Cambridge: Cambridge University Press).

Winter, Y. (2001) 'Plural Predication and the Strongest Meaning Hypothesis', Journal of Semantics, 18: 333-365.

Yanovich, I. (2005) 'Choice-functional series of indefinite pronouns and Hamblin semantics' in E. Georgala and J. Howell (eds.) Proceedings of SALT XV. (Ithaca, NY: CLC Publications), pp. 309-326.

Zimmerman, E. (2000) 'Free Choice Disjunction and Epistemic Possibility', Natural Language Semantics, 8: 255-290. 